
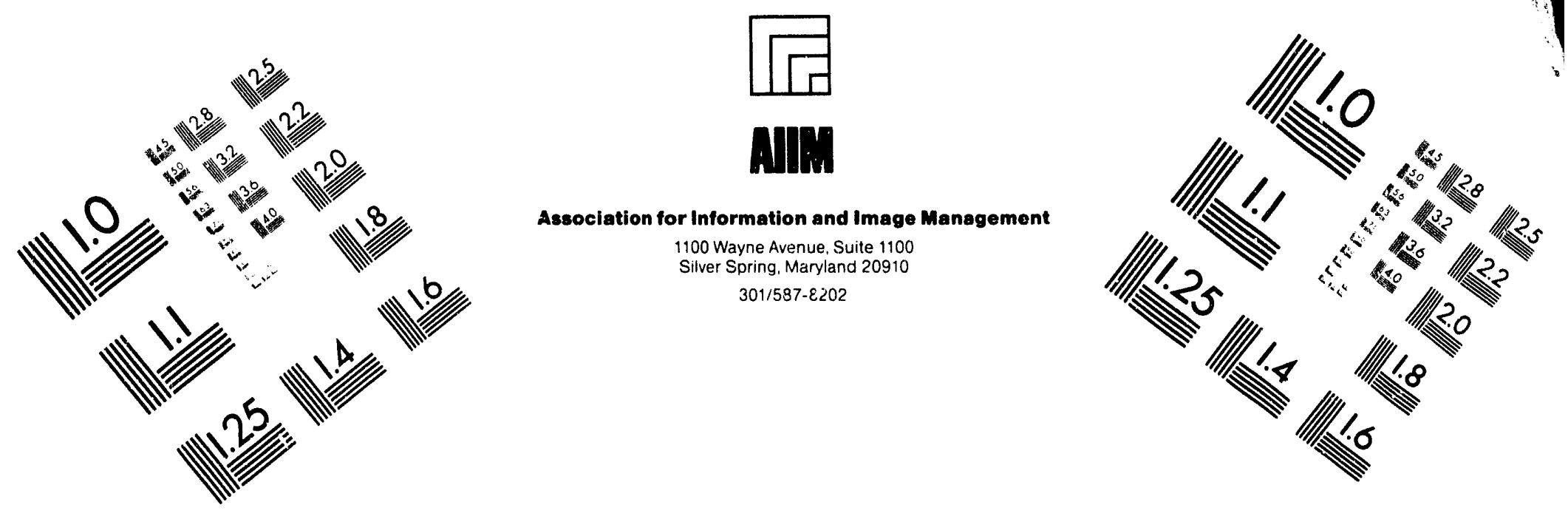

\title{
Centimeter
}

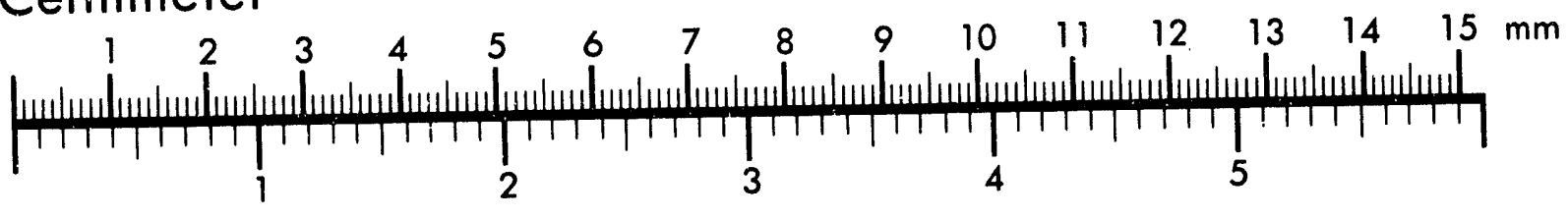
Inches
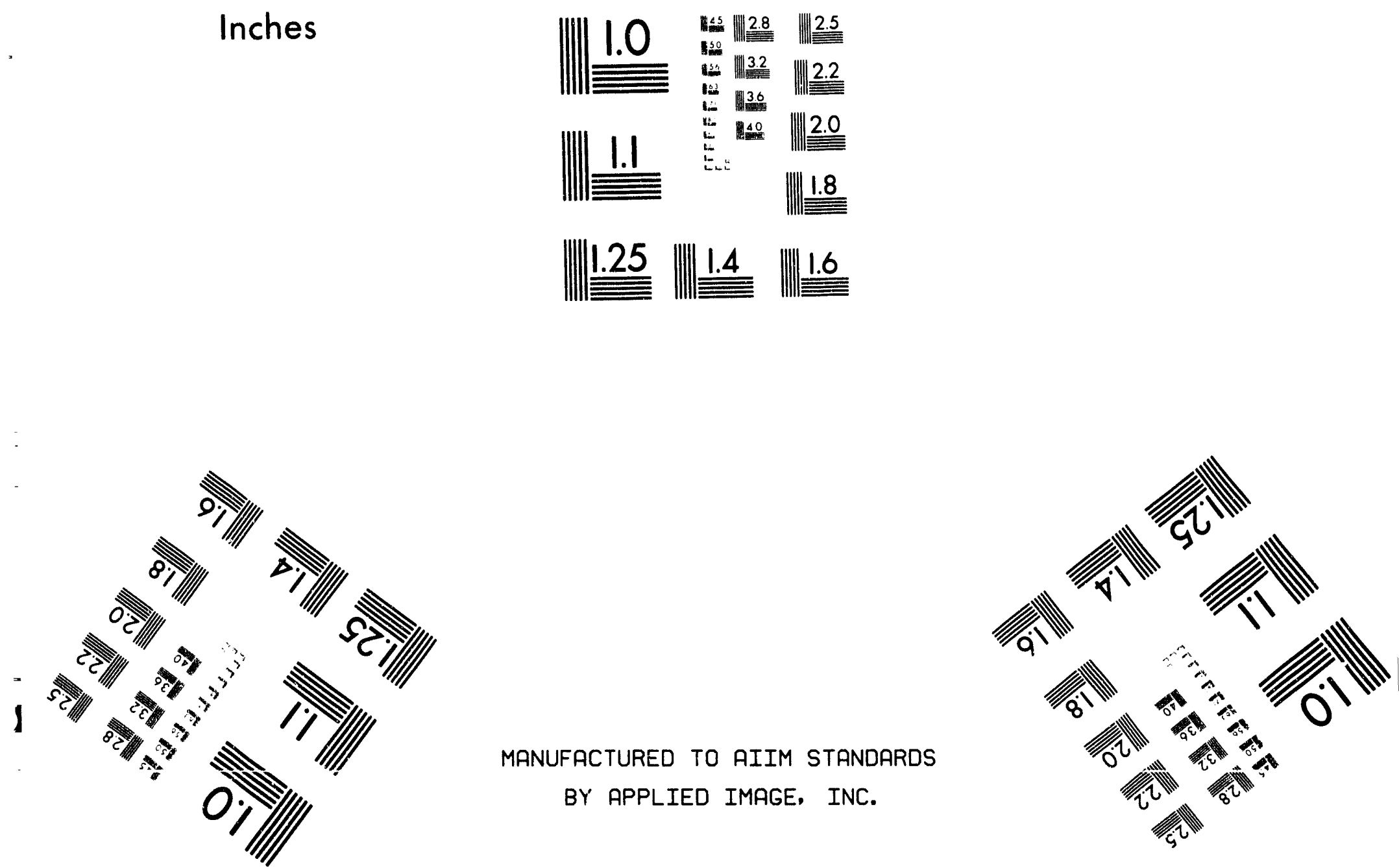

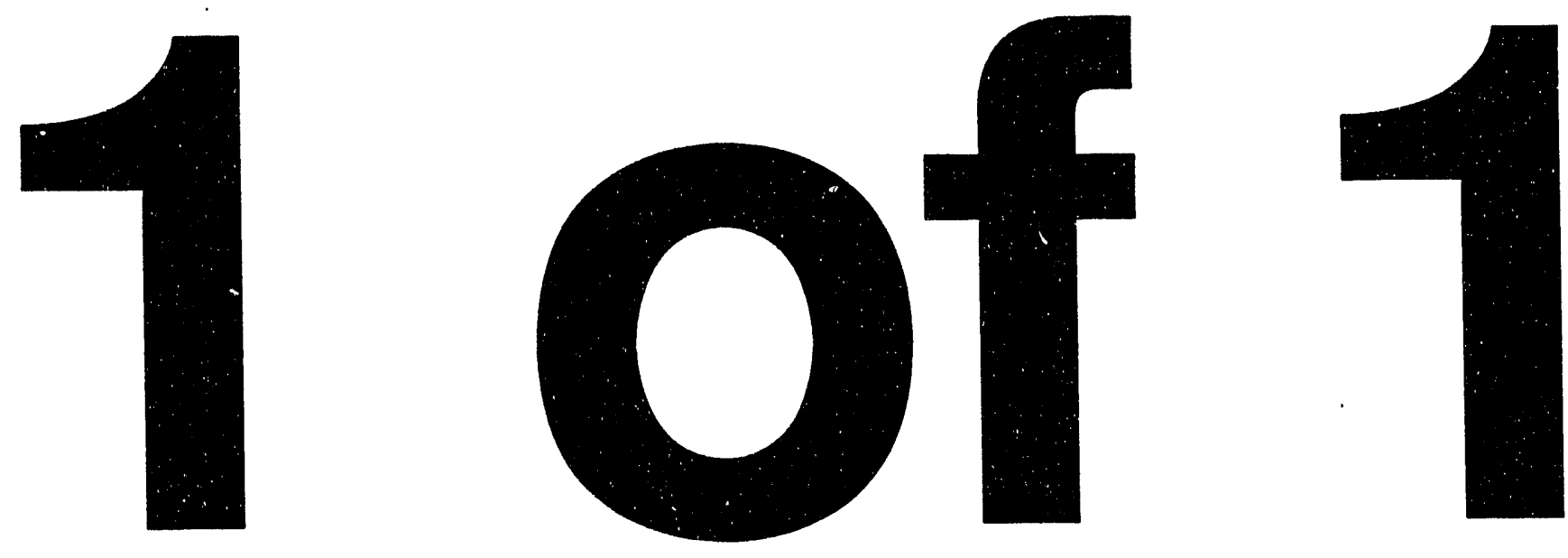


\author{
OIL RECOVERY ENHANCEMENT FROM \\ FRACTURED, LOW PERMEABILITY \\ RESER VOIRS \\ Contract No. DE-FG07-89BC14444 \\ Texas A\&M University \\ College Station, TX. \\ Contract Date: June 13, 1989 \\ Anticipated Completion: Sept. 1, 1993 \\ Government Award: $\$ 256,000$ \\ (Current Year) \\ Principal Investigator: \\ S.W. Poston \\ Project Manager \\ R. Lindsey \\ Bartlesville Ofrice \\ Reporting Period: 01/01/93 - 03/31/93
}

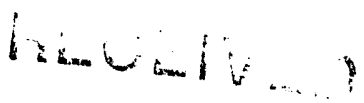

JUL 291993

OSTI

\section{Summary of Technical Progress}

\section{Subtask 1. Interpreting and Predicting Natural Fractures}

Geophysical Studies - Previous work showed that the strike of vertical fractures in the subsurface can be detected using four-component data from Vertical Seismic Profiles, VSP surveys. The strike is determined by mathematically "rotating" the traces into their principal axes. This operation minimizes the amplitudes on the traces representing horizontal displacements which are perpendicular to the horizontal source orientations. Errors in the determined orientation are caused by differences in the strengths of the orthogonally oriented surface sources and in the couplings of the horizontal geophones located in the well.

Substantial improvement in the determination of the orientation of the fractures has been obtained when these source imbalances are corrected. Further improvement is achieved when the down-hole geophones are assumed to be in the direction of the sources and their coupling variations corrected. In this case the geophone-coupling corrections are obtained

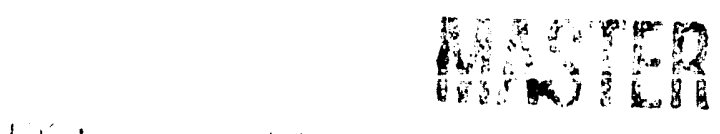


by a linear least-squares procedure which minimizes the seismic energy in the off-diagonal trace.

Investigations are continuing into the case in which the geophones are not initially oriented parallel to the source directions. A non-linear least-squares method is required to determine these corrections. The method leads to multiple-possible fracture-orientation determinations and to an unstable behavior.

Three additional, 9-component, VSP data sets were received from Chevron Oil Company. These data sets have been put into memory on the computer and preliminary processing and editing have been performed. We expect to spend maximum effort on these data sets during the summer, June through August, 1993.

Another student has been working on a combined p-wave/s-wave data set from Burleson County, Texas for the Austin Chalk formation. The purpose of this study is to determine the advantages in imaging or detecting fractures when the two types of data are available. The student is working on this project as part of his Master of Science Thesis and his effort has been at no cost to the project. We expect him to complete his study and graduate during the early part of the summer. Preliminary results indicate that the signal-tonoise ratio of the data sets may be too low to extract much meaningful information.

Geological Studies - Progress during the quarter has dealt with the acquisition and analysis of FMS data from wells in the Giddings and Pearsall Fields, S. Texas, and correlation of results to previously obtained outcrop data.

Initial studies from a borehole in the Giddings Field showed that only one fracture set striking NE and essentially vertical was developed in the subsurface. Extension fractures of this orientation would follow exactly the regional trend expected from extrapolation of fault traces from the nearest outcrops. In addition, however, this fracture set is oriented essentially perpendicular to the axis of the nearly horizontal wellbore. The fact that only one fracture set was developed was an unexpected result because at least two orthogonal sets were found developed at the outcrop. Therefore, we had to question whether or not the identification of only one set was the result of FMS sampling bias or because drilling the borehole itself had introduced fractures normal to the borehole axis or indeed were the measurements a valid assessment of the orientation of natural fractures in the subsurface?

The distribution of fracture spacing in the well located in the Pearsall Field turns out to be essentially identical to that in the well located in the Giddings Field. Fracture spacing in the borehole from the Pearsall Field varies from 1 to 10 per foot with some of the highest spacing correlating with low gamma ray values. That in the well from the Giddings Field varies from $<1$ to 12 per foot and correlates similarly with the gamma ray values, i.e., the 
greatest fracture spacing seem to correlate with the lower gamma ray values. The inverse correlation between high fracture density and low gamma ray is not surprising in that gamma ray values often correlate with clay content. Rock strength increases with decreasing clay content and therefore so would fracture abundance increase with decreasing clays, i.e., increasing gamma ray values.

Fracture aperture data from the well in the Giddings Field show apertures ranging from $0.02 \mathrm{~mm}$ to $4.0 \mathrm{~mm}$. Fracture apertures from the well in the Pearsall Field range from $0.002 \mathrm{~mm}$ to $2.0 \mathrm{~mm}$ with an estimated average between 0.1 and $1.0 \mathrm{~mm}$. These apertures are not calibrated and thus reduced to absolute values. When not calibrated the aperture data are valid only for relative comparisons within a given borehole survey. Accordingly, there are depths within each borehole where fracture apertures are consistently wider than at other depths. Our work is not yet sufficiently advanced to correlate these observations with the details of the structural stratigraphy.

\section{Subtask 2: Relating Recovery to Well-Log Signatures}

Geological Studies - Petrographic analysis of microseams was conducted on 16 thin sections to determine the gross composition and relationship of seams to microfractures. The observations indicate a geometric relation of microfractures that suggests propagation through the rock matrix. Analysis of microseams was conducted on selected samples of the Austin Chalk by means of electron microprobe. Aluminum and silicon in the insoluble residue found in two seams indicates the presence of clay minerals. Pyrite is also common in both the seams and in the rock matrix. Work was interrupted because of equipment failure. Analysis will be continued when equipment problems are corrected. Organic analysis will be conducted by means of cathode luminescence to detect the amount of kerogen and biturnen in the seams and in the microfractures.

\section{Subtask 3: Laboratory Studies of the Imbibition Process} spent.

No progress was engendered in this area because all of the research money has been

\section{Subtask 4; Mathematical Modeling}

Semi-Analytical Modeling - The core face flushing imbibition experiments at elevated temperatures and pressures were performed on a cream chalk core in Subtask 3. The semianalytical model was used to describe the laboratory imbibition oil recovery behavior by plain water and carbonated waterflood at $70^{\circ} \mathrm{F}, 110^{\circ} \mathrm{F}$ and $150 \circ \mathrm{F}$. The experimental conditions and results of matching of oil recovery at 70 of were reported in the previous 
quarter reports. In this quarter the semi-analytical model is used to simulate the oil recovery behavior of the laboratory tests at $110^{\circ} \mathrm{F}$ and $150 \mathrm{~F}$. The semi-analytical model matches the laboratory oil recovery reasonably well when the exponential imbibition rate constant $(\lambda)$ and the unitary maximum recoverable oil $(R \alpha)$ were adjusted. The semianalytical model appears to be useful for providing a quick initial estimate of oil recovery performance for imbibition carbonated waterflooding when laboratory test data are available.

Numerical Modeling - The core face flushing method was used to study the imbibition oil recovery from a chalk core in Subtask 3. The compositional, dual-porosity numerical model (COMABS) is used to describe the laboratory imbibition oil recovery obtained in Subtask 3.

The cylindrical core is idealized by using a rectangular grid system which is show.. in Fig. 1. The rock and fluid properties of the fracture and matrix systems are tabulated in Table 1 A linear, three-layer numerical model is used. Each layer was subdivided into five grid blocks; the water or carbonated water is injected into the 5th block of the fracture system at the third layer. Oil and water are produced from the 5th block of the first layer.

Two phase flow is implemented in the numerical simulation assuming the entire simulating system is above the bubble point. The $\mathrm{CO}_{2}$ is partitioned into the oil and water phase according to their individual solubilities. The oil viscosity reduction, the oil density change, the swelling of oil volume and the residual oil saturation are quantified in the numerical simulation to reflect the partitioning or diffusion of the $\mathrm{CO}_{2}$. The transmissibility of the water and oil phases are updated correspondent to the concentration of $\mathrm{CO}_{2}$ in each phase.

Fig. 2 shows the imbibition oil recoveries obtained by plain water, 2.3 wt. $\%, 4.0$ wt. $\%$, and $5.5 \mathrm{wt}$. \% carbonated water. The simulated results matched the laboratory recovery very well. The simulator provides the oil and water saturation distributions in the fracture and matrix systems. 


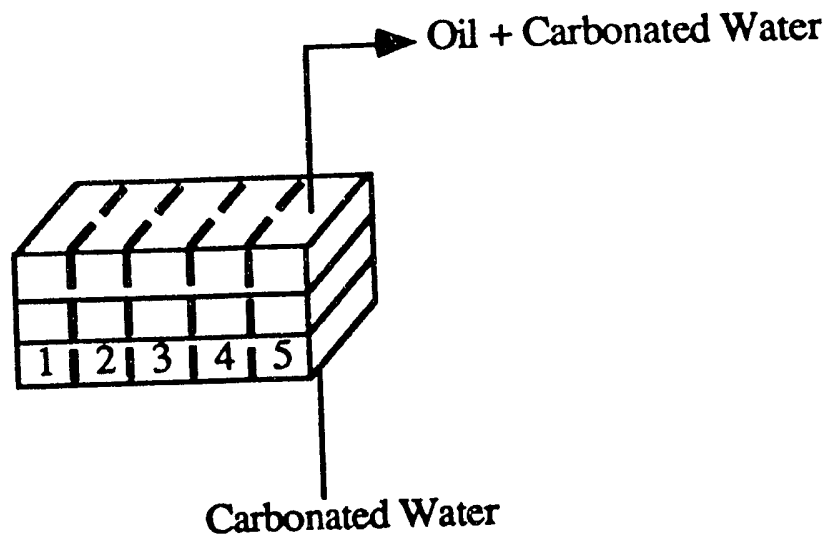

Fig. 1 - Grid system for dual-porosity simulation.



Fig.2 - Matching of imbibition oil recovery provided by plain water and carbonated water 
Table 1 - Rock and Fluid Properties of Fracture and Matrix Systems

No. of hydrocarbon components

$$
\begin{aligned}
& =1\left(\mathrm{C}_{10}\right) \\
& =5 \times 1 \times 3 \\
& =1000 \mathrm{psi} \\
& =5 \times 1 \times 1 \\
& =5 \times 1 \times 3 \\
& =0.3 \mathrm{~cm}^{3} / \mathrm{min} \\
& =0.09 \\
& =500 \mathrm{psi}
\end{aligned}
$$

\begin{tabular}{|c|c|}
\hline \multicolumn{2}{|c|}{ Fracture System Properties } \\
\hline $\begin{array}{l}\mathrm{kx}_{\mathrm{x}} \& \mathrm{ky}_{\mathrm{y}} \\
\mathrm{L}_{\mathrm{x}} \mathrm{L}_{\mathrm{y}} \& \mathrm{~L}_{\mathrm{z}} \\
\mathrm{L}_{\mathrm{wi}}\end{array}$ & $\begin{array}{l}=9,000 \mathrm{md} \\
=0.4 \mathrm{in} \\
=0.8862 \mathrm{in} \\
=0.0\end{array}$ \\
\hline $\begin{array}{l}\phi \\
\mathrm{P}_{\mathrm{c}} \\
\mathrm{k}_{\mathrm{rw}}\end{array}$ & $\begin{array}{l}=0.03 \\
=0 \\
=S_{w}\end{array}$ \\
\hline
\end{tabular}

Matrix System Properties

$\mathrm{kx}_{\mathrm{x}} \& \mathrm{ky}_{\mathrm{y}}=9.1 \mathrm{md}$

$\begin{array}{ll}\mathrm{S}_{\mathrm{wi}} & =0.2 \\ \phi & =0.23 \\ \mathrm{P}_{\mathrm{c}} & =\mathrm{f}\left(\mathrm{S}_{\mathrm{w}}\right) \\ \mathrm{k}_{\mathrm{rW}} & =\mathrm{f}\left(\mathrm{S}_{\mathrm{W}}\right)\end{array}$



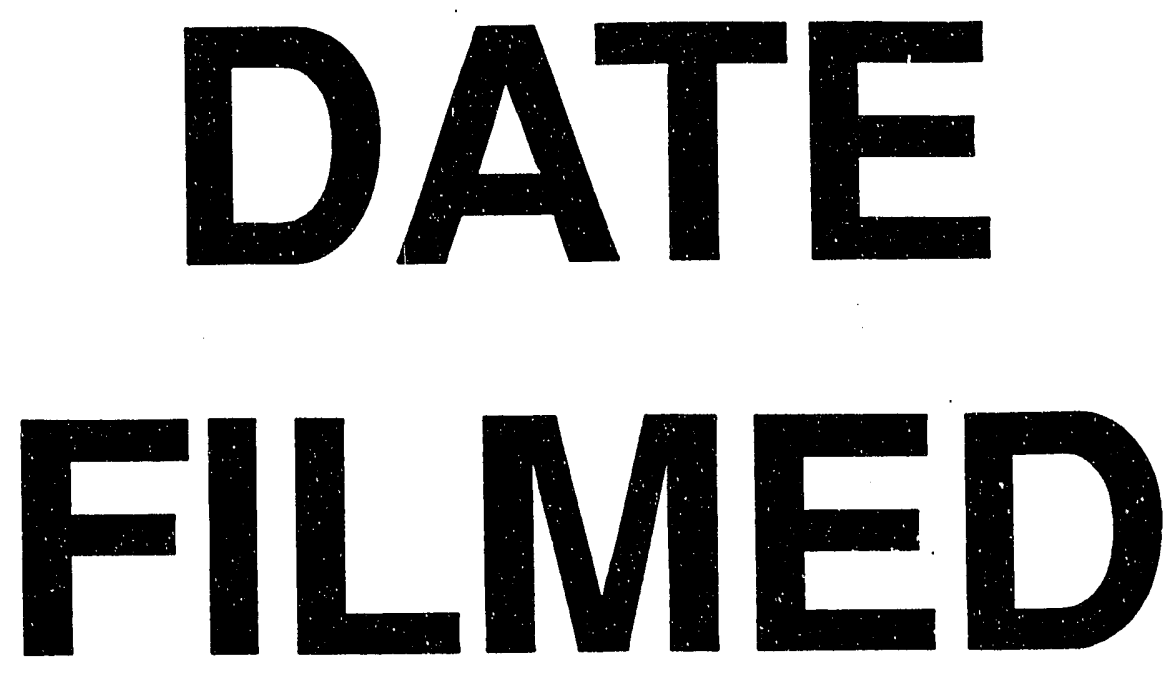

$8 / 18 / 93$
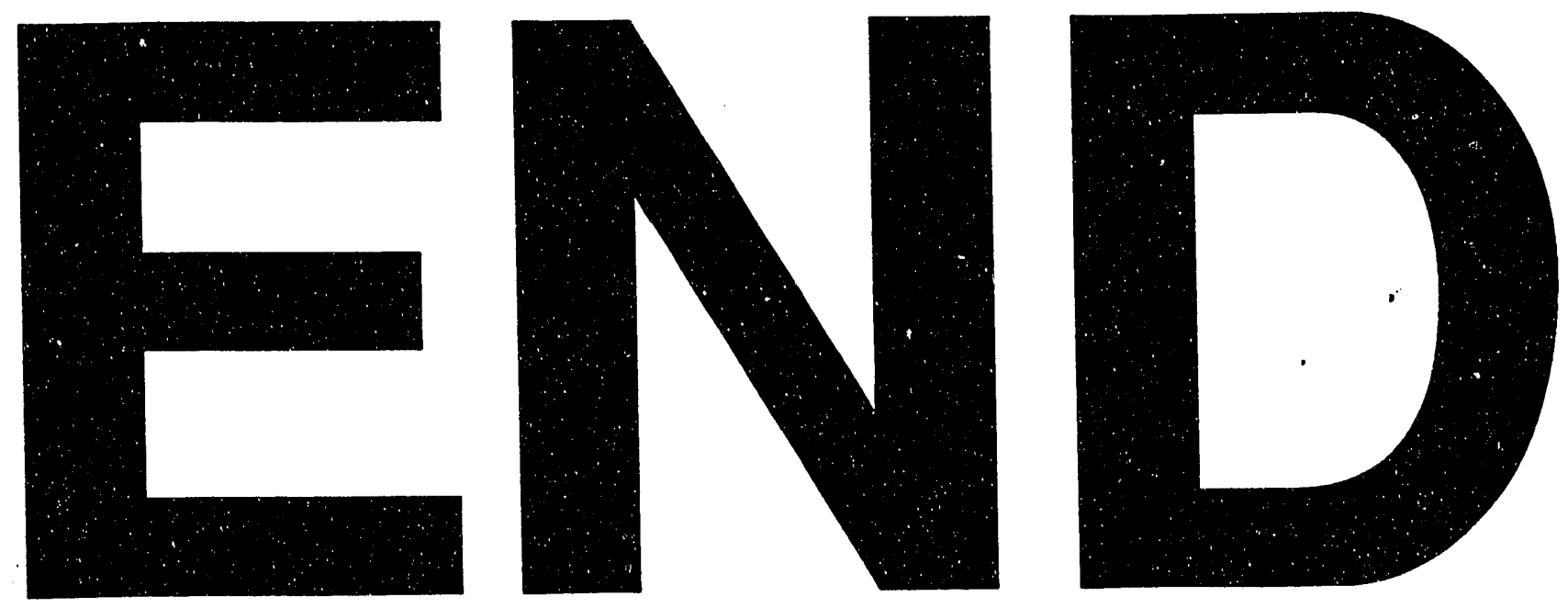
